\title{
Ethanol tolerance and alcohol dehydrogenase activity in Australian populations of Drosophila simulans
}

\author{
P. R. Anderson and \\ J. G. Oakeshott
}

Department of Population Biology, Research School of Biological Sciences, The Australian National University, P.O. Box 475, Canberra City, A.C.T. 2601, Australia.

\begin{abstract}
Ninety-seven isofemale lines from 20 Australian populations of $D$. simulans collected along an $18^{\circ}$ latitudinal gradient were assayed for adult weight, alcohol dehydrogenase activity and ethanol tolerance. No significant variation among lines was found for weight, but ADH activity and ethanol tolerance varied significantly among isofemale lines within, although not between, populations. The latitudinal homogeneity of both characters in Australia is consistent with similar results reported previously for this species in the northern hemisphere. However, the results contrast with the latitudinal clines in activity and tolerance which have been reported in populations of the sympatric sibling species $D$. melanogaster in both hemispheres. The contrast suggests that the characters are under different selective pressures in the two species.
\end{abstract}

\section{INTRODUCTION}

Most patterns of geographic variation in allele frequency can be explained by either stochastic or selective processes, depending on the assumptions made about migration and population size (Lewontin, 1974). However, stochastic explanations can be discounted if the pattern for a particular polymorphism is found to recur across separate patches of a species distribution and across sibling species with similar ecologies. We have previously reported such recurrence for two electrophoretically detectable enzyme polymorphisms shared by the cosmopolitan sibling species Drosophila melanogaster and D. simulans (Anderson and Oakeshott, 1984). Populations of the two species in both hemispheres show consistent latitudinal clines in the frequencies of shared Est-6 alleles and consistent latitudinal homogeneity for the frequencies of shared Pgm alleles. Notwithstanding the contrasting geographic patterns for the two polymorphisms, we concluded that the consistency of the pattern for each polymorphism across the two hemispheres and the species barrier was good evidence for the action of natural selection. Furthermore, we suggested that the consistency across species indicated similar mechanisms of selection on each polymorphism in the two species.
Here we complete a comparison of latitudinal patterns of variation in both hemispheres and species for quantitative characters concerned with tolerance to environmental ethanol. Ethanol tolerance is one of the very few characters of possible ecological relevance in which the two species have been shown to differ (Parsons, 1983; Anderson, 1985). In laboratory tests ethanol tolerance is higher in $D$. melanogaster than $D$. simulans and it has been claimed that this difference underlies the greater utilisation by wild $D$. melanogaster of wineries (McKenzie, 1974; Monclus and Prevosti, 1979; Marks et al., 1980) and high alcohol fruit habitats (Oakeshott et al., 1982).

It is presently unclear whether latitudinal patterns of variation in ethanol tolerance differ consistently between the two species. For $D$. melanogaster, ethanol tolerance clearly increases with increasing distance from the equator in both the northern and southern hemispheres (David and Bocquet, 1975a; Stanley and Parsons, 1981; Anderson, 1982; Cohan and Graf, 1985). However, for D. simulans, ethanol tolerance is apparently unrelated to latitude in the northern hemisphere (David and Bocquet, 1975a), while in the southern hemisphere evidence based on only three populations suggests a latitudinal cline parallel to that for D. melanogaster (Stanley and Parsons, 1981). 
If substantiated by further sampling, a latitudinal cline for tolerance in $D$. simulans in the southern hemisphere would negate the consistency of the geographic patterns both across species and across continents within $D$. simulans. It would then be difficult to support an hypothesis that natural selection underlies the geographic variation in tolerance in preference to an explanation based on stochastic processes during colonisation and migration events. We have therefore assayed the ethanol tolerance of 20 recently captured Australian populations of $D$. simulans covering an $18^{\circ}$ latitudinal range. We have also screened these populations for two characters thought to contribute to ethanol tolerance, namely weight (Oakeshott and Gibson, 1981) and the activity of the enzyme alcohol dehydrogenase (ADH; Gibson and Oakeshott, 1982).

\section{MATERIALS AND METHODS}

The 20 localities from which the experimental populations were collected were Mt. Molloy $\left(16^{\circ} 41^{\prime} \mathrm{S}, 143^{\circ} 20^{\prime} \mathrm{E}\right)$, Cairns $\left(16^{\circ} 55^{\prime} \mathrm{S}, 145^{\circ} 45^{\prime} \mathrm{E}\right)$, Mareeba north $\left(17^{\circ} 0^{\prime} \mathrm{S}, 145^{\circ} 26^{\prime} \mathrm{E}\right)$, Mareeba south $\left(17^{\circ} 0^{\prime} \mathrm{S}, 145^{\circ} 26^{\prime} \mathrm{E}\right)$, Innisfail $\left(17^{\circ} 32^{\prime} \mathrm{S}\right.$, $\left.146^{\circ} 1^{\prime} \mathrm{E}\right), \quad$ Ravenshoe $\left(17^{\circ} 36^{\prime} \mathrm{S}, \quad 145^{\circ} 59^{\prime} \mathrm{E}\right)$, Ingham $\left(18^{\circ} 39^{\prime} \mathrm{S}, \quad 146^{\circ} 10^{\prime} \mathrm{E}\right), \quad$ Townsville $\left(19^{\circ} 16^{\prime} \mathrm{S}, 146^{\circ} 49^{\prime} \mathrm{E}\right)$, Ayr $\left(19^{\circ} 34^{\prime} \mathrm{S}, 147^{\circ} 29^{\prime} \mathrm{E}\right)$, Mackay $\left(21^{\circ} 9^{\prime} \mathrm{S}, 149^{\circ} 11^{\prime} \mathrm{E}\right)$, Rockhampton $\left(23^{\circ} 22^{\prime} \mathrm{S}, 150^{\circ} 32^{\prime} \mathrm{E}\right)$, Maryborough $\left(25^{\circ} 32^{\prime} \mathrm{S}\right.$, $\left.152^{\circ} 25^{\prime} \mathrm{E}\right)$, Gympie $\left(26^{\circ} 11^{\prime} \mathrm{S}, 152^{\circ} 40^{\prime} \mathrm{E}\right)$, Nambour $\left(26^{\circ} 38^{\prime} \mathrm{S}, 152^{\circ} 58^{\prime} \mathrm{E}\right)$, Brisbane $\left(27^{\circ} 28^{\prime} \mathrm{S}\right.$, $\left.153^{\circ} 1^{\prime} \mathrm{E}\right)$, Allora $\left(28^{\circ} 2^{\prime} \mathrm{S}, 151^{\circ} 59^{\prime} \mathrm{E}\right)$, Kempsey $\left(31^{\circ} 5^{\prime} \mathrm{S}, 152^{\circ} 50^{\prime} \mathrm{E}\right)$, Taree $\left(31^{\circ} 54^{\prime} \mathrm{S}, 152^{\circ} 29^{\prime} \mathrm{E}\right)$, Sydney $\left(33^{\circ} 53^{\prime} \mathrm{S}, 151^{\circ} 13^{\prime} \mathrm{E}\right)$ and Adelaide $\left(34^{\circ} 56^{\prime} \mathrm{S}, 138^{\circ} 36^{\prime} \mathrm{E}\right)$. About five isofemale lines were established from each collection, giving a total of 97 isofemale lines. The assays described below were carried out after these lines had spent four or five generations in the laboratory. Generally two replicate cultures of each isofemale line were assayed. All assays were carried out on adults aged six to eight days since emergence at $22^{\circ} \mathrm{C}$.

$\mathrm{ADH}$ activity was assayed in one homogenate of about 20 weighed adult males from each replicate culture. The assay utilised 2-propanol as a substrate and followed the method and standard conditions of Chambers et al. (1981).

Ethanol tolerance was estimated for two cohorts of up to 50 flies for each sex from each replicate culture. The two cohorts were tested on standard medium supplemented with 3.5 per cent and 5 per cent ethanol respectively. Flies were left on the ethanol food for 7 days, after which time the survivors and casualties were counted. The number of replicate cultures assayed for tolerance was smaller for males than for females, due to the use of many males in the $\mathrm{ADH}$ activity assays above.

The six variables to be analysed were thus the weight of adult males, ADH activity in adult males, the survival percentages of females on 3.5 per cent and 5 per cent ethanol (F3.5 and F5), and the survival percentages of males on 3.5 per cent and 5 per cent ethanol (M3.5 and M5). Before statistical analysis, weight and $\mathrm{ADH}$ activity were logarithmically transformed and the tolerance variables were angularly transformed.

\section{RESULTS}

Fig. 1 shows the variation among the 20 populations for all six variables. In table 1 the data for each variable have been subjected to a nested analysis of variance in order to estimate the proportion of variance among populations, the proportion among lines within populations and the proportion among replicate cultures within lines. Weight was not found to vary significantly among lines either within or between populations. However, there was considerable variation in $\mathrm{ADH}$ activity among lines, the largest value being $2 \cdot 7$ times that of the smallest. The ADH activity variation was significant among lines within populations but not among populations. Ethanol tolerance also varied considerably among lines, for example from 12 per cent to 100 per cent for the least severe test, F3.5. Again there was no significant variation among populations. However,

Table 1 Nested analyses of variance for weight (WT), ADH activity (ADH) and four measures of ethanol tolerance (F3.5, F5, M3.5 and M5). Numbers given are the percentages of the total sums of squares among populations, among isofemale lines within populations and among replicate cultures within lines

\begin{tabular}{lcccccc}
\hline $\begin{array}{l}\text { Source of } \\
\text { variation }\end{array}$ & WT & ADH & F3.5 & F5 & M3.5 & M5 \\
\hline $\begin{array}{l}\text { Populations } \\
\text { Lines }\end{array}$ & 11 & 15 & 11 & 20 & 11 & 30 \\
$\begin{array}{l}\text { Replicates } \\
\text { (No. of cultures }\end{array}$ & 45 & $59 \ddagger$ & $52 \dagger$ & $62^{*}$ & 65 & 55 \\
assayed) & $(191)$ & $(188)$ & 37 & 18 & 23 & 15 \\
& & & & & &
\end{tabular}

${ }^{*} \mathrm{p}<0.05, \quad \dagger \mathrm{p}<0.01, \quad \neq \mathrm{p}<0.001$ 


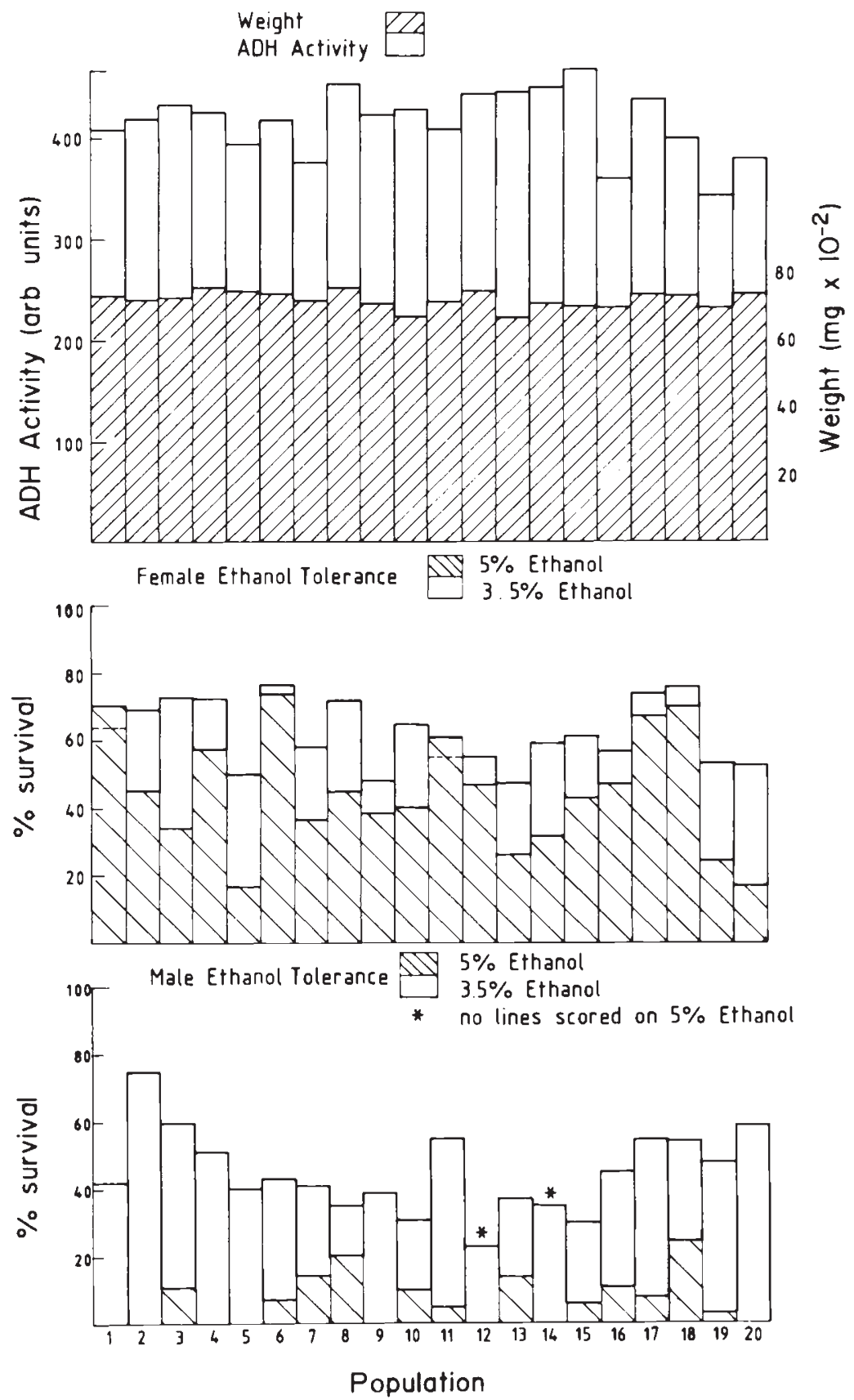

Figure 1 Mean male ADH activities, male weights, and mean percentage survivals of males and females on 3.5 per cent and 5 per cent ethanol medium for 20 Australian populations of $D$. simulans. Each population mean was calculated from the values of up to five isofemale lines. Populations are numbered in order of increasing distance from the equator (see "Materials and Methods").

differences among lines within populations were significant for F3.5 and F5. The power of the analysis to detect significant differences among lines for M3.5 and M5 was less than for F3.5 and
F5 due to the lower number of replicate cultures tested for males. The proportion of variance due to lines within populations was remarkably similar for all four measures of tolerance. 
Table 2 gives the matrix of simple correlations amongst the six variables. ADH activity was not significantly associated with any of the other measures. However, weight was positively associated with all four tolerance measures, significantly so for F3.5 and F5. Amongst the tolerance variables all associations were positive and all except that between F3.5 and M5 were statistically significant.

Table 2 Simple correlations between weight, ADH activity, F3.5, F5, M3.5 and M5.

\begin{tabular}{lrrlll}
\hline & WT & ADH & F3.5 & F5 & M3.5 \\
\hline ADH & -0.03 & & & & \\
F3.5 & $0.14^{*}$ & 0.09 & & & \\
F5 & $0.22^{*}$ & 0.10 & $0.59 \ddagger$ & & \\
M3.5 & 0.14 & -0.12 & $0.51 \ddagger$ & $0.46 \ddagger$ & \\
M5 & 0.13 & -0.05 & 0.26 & $0.39^{*}$ & $0.39^{*}$ \\
\hline
\end{tabular}

$* \mathrm{p}<0.05, \quad \neq \mathrm{p}<0.001$.

Table 3 gives the correlation coefficients for each of the six variables with latitude, longitude and altitude. As might be expected from the absence of significant differences among populations in the analyses of variance (table 1), none of the six variables was significantly related to latitude. Nor was there any consistency in the sign of the relationship with latitude across the four tolerance variables. Amongst the 18 correlations in the table, two (weight with longitude and F3.5 with altitude) were statistically significant at the 5 per cent level, but their biological significance is unclear.

Table 3 Simple correlations of weight, ADH activity, F3.5, F5, M3.5 and M5 with latitude (LAT), longitude (LONG) and altitude (ALT)

\begin{tabular}{lcrrrrr}
\hline & WT & ADH & F3.5 & F5 & M3.5 & \multicolumn{1}{c}{ M5 } \\
\hline LAT & -0.10 & -0.11 & -0.09 & -0.08 & 0.03 & 0.09 \\
LONG & $-0.21^{*}$ & 0.10 & -0.03 & 0.09 & -0.17 & 0.22 \\
ALT & 0.08 & -0.06 & $0.18^{*}$ & 0.19 & 0.08 & -0.04 \\
\hline
\end{tabular}

${ }^{*} \mathrm{p}<0.05$

\section{DISCUSSION}

We have been unable to detect systematic geographic variation in ethanol tolerance among 20 Australian populations of $D$. simulans collected over an $18^{\circ}$ latitudinal range. This differs from the results of an earlier survey of three Australian $D$. simulans populations by Parsons and Stanley (1981), who found that tolerance in one southern collection was greater than the average in two more northerly collections.

Our failure to repeat the earlier observation cannot be explained simply by suggesting that ours were less sensitive methods of measuring tolerance. Our methods, which assess percentage survival on ethanol impregnated media, have successfully detected latitudinal variation in the tolerance of Australian populations of D. melanogaster (Anderson, 1982). And conversely, the methods of Stanley and Parsons (1981), which assess the effects of ethanol vapour on longevity, are similar to those used elsewhere to demonstrate latitudinal homogeneity of tolerance among populations of D. simulans in the northern hemisphere (David and Bocquet, 1975a). On the basis of its much larger sample size, we therefore conclude that the present study provides a more reliable description of the geographic distribution of tolerance in Australian $D$. simulans.

Results for both hemispheres are now consistent in showing latitudinal homogeneity of tolerance in $D$. simulans. The results for this species also now clearly contrast with those for $D$. melanogaster, which shows consistent latitudinal clines for tolerance in both hemispheres (David and Bocquet, 1975a; Stanley and Parsons, 1981; Anderson, 1982; Cohan and Graf, 1985). The consistent clines in $D$. melanogaster suggest that ethanol tolerance in this species is subject to natural selection. However, it is clear that if selection is acting on ethanol tolerance in $D$. simulans, the selective constraints on tolerance are different to those in D. melanogaster. This is consistent with the facts that $D$. melanogaster is relatively more abundant in wineries and high ethanol food habitats (McKenzie, 1974; Monclus and Prevosti, 1979; Marks et al., 1980; Oakeshott et al., 1982) and shows much greater overall levels of ethanol tolerance (Parsons, 1983).

Moreover, there are striking parallels in the species differences for ethanol tolerance and $\mathrm{ADH}$ activity. The latter character also shows much higher mean values in $D$. melanogaster than $D$. simulans, increases with increasing latitude in $D$. melanogaster in both hemispheres, and is unrelated to latitude in $D$. simulans in both hemispheres (Anderson, 1982; Oakeshott et al., 1982; Anderson, 1985 and the present study). Taken together, all these observations suggest that the two sibling species differ in their adaptation to environmental ethanol although, considered individually, several 
of them are difficult to interpret. (For example, there is no direct evidence of a latitudinal gradient in the ethanol levels of Drosophila food resources which might select for a tolerance cline in D. melanogaster; Anderson, 1985.)

The present results also suggest a broader context in which the ecological genetics of the two species may differ. For D. melanogaster, recurrent latitudinal associations on up to three continents have been reported for various measures of body size and weight (David and Bocquet, 1975a; 1975b), four chromosome inversions (Knibb, 1982), six enzyme polymorphisms (Oakeshott et al., 1984), ethanol tolerance and $\mathrm{ADH}$ activity (Anderson, 1982; Cohan and Graf, 1985), and possibly also lethal and semi-lethal genes (Ives, 1945). In contrast, the only example to date of latitudinal associations recurring across continents in D. simulans involves alleles of the Esterase-6 enzyme locus (Anderson and Oakeshott, 1984). Latitudinal variation in body size and weight has been recorded for $D$. simulans in the northern hemisphere (David and Bocquet, 1975a; 1975b) but the present study reveals no such pattern south of the equator.

There is already evidence that $D$. simulans shows less genetic variation within populations than D. melanogaster for some morphological characters (David and Bocquet, 1975a; 1975b; Anderson, 1985), and for inversion (Ashburner and Lemeunier, 1976) and allozyme (Gonzalez et al., 1982; Anderson, 1985) polymorphisms. The results summarised above suggest that $D$. simulans also shows less systematic variation between populations than D. melanogaster. This could reflect different adaptive responses to environmental variability, $D$. melanogaster being more likely to segregate differently adapted genotypes and $D$. simulans having greater developmental flexibility (Parsons, 1983). However, the little experimental evidence available suggests that this is not the case; D. simulans in fact shows less developmental flexibility under various temperature regimes (Levins, 1969; McKenzie, 1978). An alternative explanation for the lower level of genetic variation between populations of $D$. simulans is that migration rates are higher in this species; however we are unaware of any data to test this proposition.

Acknowledgements We are indebted to Dr I. A. Boussy, Mr P. H. Cooke, Dr S. Easteal, Ms A. Y. Game, Dr J. B. Gibson, Dr S. W. McKechnie, Dr J. A. McKenzie, Prof. P. A. Parsons and Prof. R. C. Richmond for valuable discussions and comments on the manuscript.
REFERENCES

ANDERSON, D. G. 1982. Alcohol dehydrogenase activity and ethanol tolerance along the $A d h$ cline in Australia. In Advances in Genetics, Development and Evolution of Drosphila (ed. Lakovaara, S.), pp. 263-272. Plenum Press, New York.

ANDERSON, P. R. 1985. Ph.D. Thesis, Australian National University, Canberra.

ANDERSON, P. R. AND OAKESHOT,, J. G. 1984. Parallel geographic patterns of allozyme variation in two sibling Drosophila species. Nature, 308, 729-731.

ASHBURNER, M. AND LEMEUNIER, F. 1976. Relationships within the Drosophila melanogaster subgroup of the genus Drosophila, Sophophora: Part 1. Inversion polymorphisms in Drosophila melanogaster and Drosophila simulans. Proc. R. Soc. Lond. B, 19, 137-157.

CHAMBERS, G. K., Wilks, A. V. AND GibSON, J. B. 1981. An electrophoretically cryptic alcohol dehydrogenase variant in Drosophila melanogaster: III. Biochemical properties and comparison with common enzyme forms. Aust. J. Biol. Sci., 34, 625-637.

COHAN, F. M. AND GRAF, J-D. 1985. Latitudinal cline in Drosophila melanogaster for knockdown resistance to ethanol fumes and for rates of response to selection for further resistance. Evolution, 39, 278-293.

DAVID, J. R. AND BOCQUET, C. 1975a. Similarities and differences in latitudinal adaptation of two sibling Drosophila species. Nature, 257, 588-590.

DAVID, J. R. AND BOCQUET, C. 1975b. Evolution in a cosmopolitan species: Genetic latitudinal clines in Drosophila melanogaster wild populations. Experientia. 31, 164166.

GIBSON, J. B. AND OAKESHOTT, J. G. 1982. Tests of the adaptive significance of the alcohol dehydrogenase polymorphism in Drosophila melanogaster: Paths, pitfalls and prospects. In Ecological Genetics and Evolution (eds. Barker, J. S. F and Starmer, W. T.), pp. 291-306. Academic Press, Sydney.

GONZALEZ, A. M., CABRERA, V. M., LARRUGA, J. M. AND GULLON, A. 1982. Genetic distance in the sibling species Drosophila melanogaster, Drosophila simulans and Drosophila mauritiana. Evolution, 37, 1128-1133.

IVES, P. T. 1945. The genetic structure of American populations of Drosophila melanogaster. Genetics, 30, 167-196.

KNIBB, W. R. 1982. Chromosome inversion polymorphisms in Drosophila melanogaster: II. Geographic clines and climatic associations in Australiasia, North America and Asia. Genetica, 58, 213-221.

LEVINS, R. 1969. Thermal acclimation and heat resistance in Drosophila species. Amer. Nat., 103, 483-499.

LEWONTIN, R. C. 1974. The Genetic Basis of Evolutionary Change. Columbia Univ. Press, New York.

MCKENZIE, J. A. 1974. The distribution of vineyard populations of Drosophila melanogaster and Drosophila simulans during vintage and non-vintage periods. Oecologia (Berlin), 15, $1-16$.

MCKENZIE, J. A. 1978. The effect of developmental temperature on population flexibility in Drosophila melanogaster and Drosophila simulans. Aust. J. Zool., 26, 105-112.

MARKS, R. W., BRITTNACHER, J. G., MCDONALD, J. F., PROUT, T. AND AYALA, F. J. 1980. Wineries, Drosophila and ADH. Oecologia (Berlin), 47, 141-144.

MONCLUS, M. AND PREvosTI, A. 1979. Cellular habitat and Drosophila populations. Genet. Iber., 30-31, 189 202. 
OAKESHOTT, J. G. AND GIBSON, J. B. 1981. Is there selection by environmental alcohol on the alcohol dehydrogenase locus in Drosophila melanogaster? In Genetic Studies of Drosophila Populations (eds. Gibson, J. B. and Oakeshott, J. G.), pp. 103-120. Australian National University, Canberra.

OAKESHOTT, J. G., MAY, T. W., GIBSON, J. B. AND WILLCOCKS, D. A. 1982. Resource partitioning in five domestic Drosphila species and its relationship to ethanol metabolism. Aust. J. Zool., 30, 547-556.

OAKESHOTT, J. G., MAY, T. W., GIBSON, J. B. AND WILLCOCKS, D. A. 1982a. Resource partitioning in five domestic Drosphila species and its relationship to ethanol metabolism. Aust. J. Zool., 30, 547-556.
OAKESHOTT, J. G., MCKECHNIE, S. W. AND CHAMBERS, G. K. 1984. Population genetics of the metabolically related $A d h$, Gpdh and Tpi polymorphisms in Drosophila melanogaster: I. Geographic variation in $G p d h$ and $T p i$ allele frequencies in different continents. Genetica, 63, 21-29.

OAKESHOTT, J. G., COHAN, F. M. AND GIBSON, J. B. 1985. Ethanol tolerance of $D$. melanogaster populations selected on different concentrations of ethanol supplemented media Theor. Appl. Genet., 69, 603-608.

PARSONS, P. A. 1983. The Evolutionary Biology of Colonising Species. Cambridge Univ. Press, Cambridge.

STANLEY, S. M. AND PARSONS, P. A. 1981. The response of the cosmopolitan species, Drosophila melanogaster, to ecological gradients. Proc. Ecol. Soc., Aust., 11, 121-130. 